\title{
Adult Awareness of a Youth-Focused Anti-Tobacco Campaign: Does Having Children Matter?
}

\author{
JORGE DELVA, ${ }^{1}$ NOELLA A. DIETZ, ${ }^{2}$ BRIAN PERRON, ${ }^{3}$ \\ NINIVE SANCHEZ, ${ }^{3}$ AND MICHAEL E. WOOLLEY ${ }^{4}$ \\ ${ }^{1}$ School of Social Work and Institute for Social Research, University of \\ Michigan, Ann Arbor, Michigan, USA \\ ${ }^{2}$ Department of Epidemiology and Public Health, Sylvester Comprehensive \\ Cancer Center, University of Miami Miller School of Medicine, Miami, Florida, \\ USA \\ ${ }^{3}$ School of Social Work, University of Michigan, Ann Arbor, Michigan, USA \\ ${ }^{4}$ School of Social Service Administration, University of Chicago, Chicago, \\ Illinois, USA
}

\begin{abstract}
Data from a survey of tobacco use conducted in 2001 was used to examine if Florida's youth-focused anti-tobacco media campaign, which focused on cigarette smoking, reached adults. The majority of the sample was white (87\%), high school or college educated (85\%), and over half with children (56\%). Differences in awareness and intentions to quit among adult smokers with and without children were examined. About $50 \%$ of adults were aware of the campaign and the awareness of the tobacco industry manipulation theme was associated with intentions to quit, independent of having children. These findings provide evidence that youth-targeted anti-tobacco media campaigns can reach adults; however, to change the behavior of adults who smoke, it may not be appropriate to have a "one-size-fits-all" program. The study's limitations are noted.
\end{abstract}

Keywords cigarettes; youth; parent-child communication; survey

\section{Introduction}

The personal, social, and economic consequences of tobacco use have been welldocumented since the publication of the initial Surgeon General's Report on Tobacco Use more than three decades ago (US Department of Health, Education, and Welfare, 1964), as well as by the 28 additional reports since then (e.g., US Department of Health and Human Services 1989, 1994, 2000, 2006). Although there had been earlier efforts to reduce tobacco use, it was not until the late 1980s and early 1990s (and largely due to

This study was funded by a grant from the Florida Department of Health, James and Esther King Biomedical Research Program, and the Swedish Council for Medical Tobacco Research. The study also received support from the Vivian A. and James L. Curtis School of Social Work Research and Training Center, University of Michigan.

Address correspondence to Jorge Delva, School of Social Work and Institute for Social Research, University of Michigan, 1080 S. University, Ann Arbor, MI 48109.E-mail: jdelva@ umich.edu. 
the reports' influences) that systematic initiatives involving surveillance, monitoring, and evaluation were launched.

Evidence suggests that adult-oriented or general population health campaigns have a positive effect on youths (Siegel and Biener, 2000). Yet, it is unclear if campaigns targeting youths have a similar impact on adults. Though the "truth" campaign is a youth targeted anti-tobacco campaign, it is a public health-based anti-tobacco media campaign. At the time of the survey in 2001, the Florida youth targeted "truth" counteradvertising campaign had been in place since 1998, potentially exposing adults and youths to the prevention campaign. Therefore, it had the potential to reach nontargeted populations, such as adults. To our knowledge, and after conducting a comprehensive literature review of studies investigating the effects that anti-tobacco or antidrug campaigns may have on adults through their children, there are no studies that have examined the questions of whether a youth-focused campaign can reach adults directly or indirectly. This is an important question to examine because it would contribute to our understanding of the effects of campaigns on individuals not initially targeted, in this case, adults. If more youth-focused campaigns were developed as opposed to targeting general populations, either because of budgetary constraints or because of their higher effectiveness, it would be informative to know if these campaigns also reach adults, a nontargeted audience.

The basic mission of the Florida Pilot Program on Tobacco Control (of which the "truth" campaign is a part) was to prevent and reduce youth tobacco use. The goals identified to accomplish this mission were: (1) to change attitudes about tobacco among youths and adults; (2) to empower youths to lead community action against tobacco; (3) to reduce availability and access of tobacco products to youths; and (4) to reduce youth's exposure to secondhand smoke (SHS). To accomplish these goals, four programmatic areas were established. These include a countermarketing media program grounded in an industry manipulation strategy with particularly hard-hitting and cutting-edge anti-tobacco advertisements. It also includes an education and training program that is particularly focused on getting tobacco use prevention education into the school curriculum, and a youth and community partnership program to facilitate grassroots activities in support of tobacco control. Finally, there also is an enforcement program that targets retailer education and violations, as well as underage persons who are in possession of tobacco products. To date, no survey has been conducted to examine the effect of Florida's youth anti-tobacco media campaign on adults. However, the media programs have the potential of reaching nontargeted populations where they can have a norming influence. This is possible because media campaigns have at least three important advantages. First, media programs are generally centrally controlled. Program managers work with a single media contractor who has sole responsibility for obtaining advertising (either producing unique programmatic advertisements or adapting and purchasing rights to existing advertisements), scheduling, and purchasing advertising rights . Second, paid media programs can be implemented more quickly and efficiently than less centrally controlled programs. Third, unlike other programs, media programs can be completely standardized. That is, although the context and environment in which advertisements are viewed cannot be controlled, the message content, number of exposures offered, mode and type of presentation, timing, and cycling can be controlled.

Tobacco control efforts have been implemented in a number of states; however, unique to Florida, the tobacco control programs concentrate on targeting youths and follow an empowerment model and channeled rebellion against the tobacco industry. The Florida program followed the Centers for Disease Control and Prevention transtheoretical model 
and behavioral change model; that is, the more a person in a targeted population is exposed to the anti-tobacco advertisements, the more likely a person's attitudes and beliefs will be influenced by the message of the campaign, thereby, influencing behavior. In contrast, most states have followed a more normative model emphasizing the idea that the adult population must be targeted to stop smoking in order for the youth population to stop smoking. In this study, we use data from a survey conducted in 2001 to examine if Florida's anti-tobacco "truth" program was effective in reaching the adult population. We tested differences in awareness of the antismoking campaign and intentions to quit among adult smokers with and without children.

\section{Methods}

\section{Sample}

Data come from a survey designed to examine the effects of a youth-targeted anti-tobacco media campaign on adults and youths in Florida. In 2001 interviews were conducted by a University Survey and Research Center, employing a computer-assisted telephone interview (CATI) system and random digit dialing (RDD). The study was designed to assess the extent to which adults in the state of Florida were aware of and could confirm items presented by the Florida anti-tobacco "truth" campaign, including assessing adult/youth tobacco use, attitudes/beliefs about tobacco use and tobacco companies, brand awareness, demographic characteristics, and quit items. The study design initially consisted of interviewing 1,000 adults aged from 30 to 50 years, who had children aged from 12 to 17 years (the age targeted by the "truth" campaign) and 1,000 adults of the same age without children. Using a publicly available vendor-generated list of telephone numbers of Florida residents, a total of 17,860 numbers were called via random digit dialing (RDD) for a period of six months. Of these numbers, 4,058 did not include an adult who met the study's eligibility criteria, 1,033 were business offices or other organization numbers (not household numbers), 3,795 consisted of nonworking numbers or fax numbers, and 5,637 consisted of numbers where no one was reached (e.g., answering machine with and without messages, no one answering the phone, busy numbers, and left message but no one returned the call). A total of 3,337 met the eligibility criteria. From February through July 2001, of these adults who met the eligibility criteria, 2,374 participated (71\%). Of all adults who participated in the study, $51 \%$ had children $(N=1,216)$. Of the 1,216 adults who had children, $977(80 \%)$ parent/youth pairs participated. Respondents were given a small check (\$5) to thank them for their participation.

When a household was contacted, the interviewer identified herself/himself as calling from the survey research center conducting a telephone survey about the Florida antitobacco campaign. The interviewer then would ask if there was an adult of eligible age available. If yes and the adult was available to participate, informed consent was obtained and the interview was conducted immediately. If the adult was not available, the adult was contacted at a later time. Once an adult agreed to participate, she/he was asked if there was a youth in the home aged from 12 to 17 years. If yes, permission was asked for that youth to participate and informed consent was obtained from the youth. The youth was interviewed immediately, if available, and if not, the youth was contacted at a later time. When adults reported more than one eligible youth to participate, the youth with the most recent birth date was selected to participate. The study protocol was approved by the university's institutional review board. 


\section{Measures}

To measure the effects of a youth-oriented anti-tobacco media campaign on a nontargeted population (i.e., adults), all respondents were asked questions about their cigarette use (both lifetime and current), their intentions to quit, as well as campaign and advertising awareness measures. The questions utilized in this survey are based on validated instruments utilized on prior evaluations of the Florida "truth" campaign (see Arheart, Sly, Trapido, Rodríguez, and Ellestad, 2004; Sly, Hopkins, Trapido, and Ray, 2001; Sly, Heald, and Ray, 2001). Demographic data such as gender, age, race/ethnicity, marital status, and education were also obtained. Finally, we also accounted for parental status (whether the adult had a child).

Intentions to Quit Smoking. Respondents who were current smokers were asked if they were "planning to quit smoking cigarettes in the next 30 days?" We created a dichotomous variable: Yes $=1$; No $=0$.

Parental Status. Adults were asked if they had children in the targeted age range of 12 to 17 . Adults with children were coded as " 1 " and adults without children were coded as "0."

Current Cigarette Use. Current smoking status was assessed by asking respondents: "During the past 30 days, how many days did you smoke cigarettes, even a puff or two?" Current smokers were coded as " 1 " and nonsmokers as " $0 . "$

Campaign Awareness. Several questions measured the extent to which adults were aware of the anti-tobacco campaign. These are described next.

Confirmed "truth" campaign theme/slogan. Respondents were asked two questions: "Are you aware of any anti-tobacco or antismoking campaign that is now taking place in Florida?" and "What is the theme or slogan of this campaign?" Respondents who answered in the affirmative to the first question then were asked the next question identifying the campaign theme. Those who positively identified the "truth" campaign theme/slogan were considered to have confirmed the "truth" campaign theme. Broad or general responses such as "cigarettes kill" or "smoking is bad" were not counted as confirming the message of the campaign. This variable was dummy-coded: $1=$ confirm, $0=$ did not confirm.

Confirmed awareness of the "truth" logo. Brand awareness was assessed by asking respondents to confirm on another key component to the program, identifying the antitobacco "truth" logo. This measure of campaign awareness is derived from the concept of "brand awareness" (Sly et al., 2001). In this instance, the anti-tobacco or antismoking brand is represented by the "truth" logo. Respondents were asked to tell the interviewer what they thought of when they hear the word "truth" or see the word "truth" inside an oval. Confirmed answers included those answers where respondents were able to give one of the campaign's major message themes, such as "tobacco companies target kids" or "kids are leading the effort to fight tobacco." Responses from individuals who gave answers that included more general responses, such as "don't smoke," were coded as unconfirmed. Response categories were coded: $1=$ confirm logo, $0=$ did not confirm.

Confirmed awareness of the anti-tobacco media advertisements event and theme. Respondents were asked a series of three questions for each of the 10 advertisements underway during the media campaign. The first question asked the respondents if they "have recently seen an anti-tobacco advertisement that $[-]$..." The blank is filled in with a cue to describe the particular advertisement. If participants give a positive response to this item, they are asked two additional items with no cues. The first question asks the respondent what happens in the advertisement (event) and the second asks the respondent what the major message was from the advertisement (theme). Correct responses had to contain an accurate 
description of the advertisement or the major theme. For this study, we coded the confirmed event and the confirmed theme as categorical variables (confirm $=1$, did not confirm $=0$ ).

Confirmed awareness of tobacco industry manipulation theme. This was assessed using participants' responses to three items about the extent to which they were aware of the industry manipulation theme set forth by the "truth" campaign. These items are: "You feel tobacco companies are just trying to use you," "Tobacco companies use advertising to fool young people," and "Tobacco companies try to get young people to smoke because older people quit or die." A Likert scale format was used for each item: (1) definitely agree; (2) probably agree; (3) probably disagree; and (4) definitely disagree. We created an additive industry manipulation scale with higher scores indicating greater awareness of industry manipulation. Internal consistency (Cronbach's alpha) for these items was 0.83 .

Doctor's advice to quit. We also include the following item-whether a doctor or someone in a doctor's office told them to quit smoking in the past year, with response categories dichotomized (yes $=1$; no $=0$ ).

Spouse's smoking status. Finally, respondents were asked if their spouses smoked; again, response categories were dichotomized with nonsmoking as the reference category $($ yes $=1 ;$ no $=0)$.

\section{Analysis}

The percent of respondents who confirmed campaign characteristics as a function of whether they have children and their smoking status was calculated first. Then, bivariate and multivariate logistic regression analyses were used to examine the association between having children and intentions to quit smoking in the next 30 days, as well as between intentions to quit and the confirmed campaign and advertising awareness variables, among 781 adults (33\% of the adult sample) who reported smoking in the past 30 days. Demographic characteristics included in this study, and used as controls in the multivariable logistic regression analyses, were gender, age, race/ethnicity, marital status, and education.

\section{Results}

A total of $33 \%$ of adults $(N=781)$ reported smoking in the past 30 days. Forty-eight percent of adult smokers had children aged from 12 to 17 years, while $52 \%$ did not have children in this age group. Of these adult smokers, $29 \%$ were men and $71 \%$ were women. Ninetyone percent of adults were 35 years or older. The sample was comprised of $87 \%$ white, $3 \%$ black/non-Hispanic, 5\% Hispanic, and slightly over 5\% were of other racial/ethnic background. Sixty-four percent of all adults were married and $20 \%$ divorced/separated. Six percent of adult smokers had less than a high school degree, $34 \%$ had a high school degree, and $51 \%$ had completed a college degree.

As shown in Table 1 , a higher percent of adults with children $(56 \% ; n=1216)$ than adults without children $(45 \% ; n=1158)$ confirmed the "truth" campaign theme/slogan $(p<.05)$. Also, a slightly higher percentage of adults with children $(48 \%)$ than adults without children (44\%) were aware of the "truth" logo, but this difference was not statistically significant. For both measures, there were no differences based on whether or not the respondent was a current smoker. No other significant differences are observed except that among adults with children a higher percent of smokers $(38 \%)$ than nonsmokers $(30 \%)$ were aware of two or more advertisements $(p<.05)$. 
Next, we examined if having children was associated with adult smokers' intentions to quit smoking in the next 30 days. Nearly $30 \%$ of the sample expressed a willingness to quit smoking in the next 30 days, with $31 \%$ of adults with children and $27 \%$ of adults without children expressing such willingness to quit.

Table 2 reports factors associated with intentions to quit smoking using bivariate (unadjusted) and multivariate (adjusted) logistic regression models. In the bivariate models, having children was not associated with quitting smoking. Racial ethnic minorities were more likely to report intentions to quit compared to whites $(\mathrm{OR}=1.92 ; 95 \% \mathrm{CI}=1.21-3.02)$. Other factors associated with intentions to quit were awareness of the tobacco manipulation theme $(\mathrm{OR}=1.62 ; 95 \% \mathrm{CI}=1.41-1.86)$ and having been advised by a doctor to quit $(\mathrm{OR}=1.47 ; 95 \% \mathrm{CI}=1.06-2.04)$.

All the variables examined in the bivariate analyses were then entered into a logistic regression model, using the same outcome variable (i.e., intentions to quit in the next 30 days). In this analysis, the only variable significantly associated with intentions to quit was having an awareness of the tobacco industry's manipulation $(\mathrm{OR}=1.65 ; 95 \% \mathrm{CI}=$ $1.33-2.04)$.

\section{Discussion}

The anti-tobacco campaign targeted 12-17-year-olds in an effort to prevent them from starting to smoke. In this study, we were concerned with whether this campaign could have any unintended consequences, such as reaching a broader audience than the one expected. Our goal was to examine if the awareness adults may have had about the campaign varied

Table 1

Adult awareness the Florida "truth" anti-tobacco campaign by whether they have children aged from 12 to 17 years and by current smoking status

\begin{tabular}{|c|c|c|c|c|c|c|c|}
\hline \multirow[b]{2}{*}{ Population } & \multirow[b]{2}{*}{$N$} & \multirow{2}{*}{$\begin{array}{l}\text { (\%) Confirmed } \\
\text { "truth" campaign } \\
\text { theme/slogan }\end{array}$} & \multirow{2}{*}{$\begin{array}{l}\text { (\%) Aware } \\
\text { "truth" } \\
\text { logo }\end{array}$} & \multicolumn{3}{|c|}{$\begin{array}{c}(\%) \text { Aware of } \\
\text { advertisements by } \\
\text { number of ads }\end{array}$} & \multirow{2}{*}{$\begin{array}{l}\text { (\%) Confirm "truth" } \\
\text { advertising } \\
\text { theme }\end{array}$} \\
\hline & & & & None & One & Two+ & \\
\hline All adults & 2374 & 50.5 & 45.9 & 48.9 & 18.7 & 32.4 & 17.2 \\
\hline Nonsmoker & 1569 & 51.6 & 46.3 & 50.2 & 18.8 & 31.0 & 20.6 \\
\hline Smoker & 1569 & 48.4 & 45.0 & 46.3 & 18.6 & 35.0 & 19.3 \\
\hline $\begin{array}{l}\text { With } \\
\text { children }\end{array}$ & 1216 & $55.5^{\mathrm{a}}$ & 47.9 & 49.1 & 17.9 & 35.0 & 21.7 \\
\hline Nonsmoker & 840 & 56.8 & 48.2 & 50.8 & 18.6 & $30.0^{\mathrm{b}}$ & 22.5 \\
\hline Smoker & 376 & 52.7 & 47.1 & 45.2 & 16.5 & $38.3^{\mathrm{b}}$ & 19.9 \\
\hline $\begin{array}{l}\text { Without } \\
\text { children }\end{array}$ & 1158 & $45.3^{\mathrm{a}}$ & 43.7 & 48.7 & 19.6 & 31.7 & 18.5 \\
\hline Nonsmoker & 729 & 45.5 & 44.0 & 49.5 & 19.1 & 31.4 & 18.4 \\
\hline Smoker & 429 & 44.8 & 43.1 & 47.3 & 20.5 & 32.2 & 18.6 \\
\hline
\end{tabular}

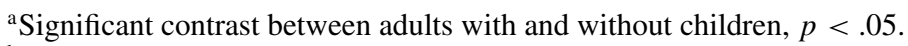

${ }^{\mathrm{b}}$ Significant variation in percents between smoker and nonsmokers among adults with children, $p<.05$. 
Table 2

Factors associated with adult smokers intentions to quit within the next 30 days $(N=781)$

\begin{tabular}{|c|c|c|c|c|c|}
\hline \multirow[b]{2}{*}{ Variables } & \multirow[b]{2}{*}{$n$} & \multicolumn{2}{|c|}{ Bivariate } & \multicolumn{2}{|c|}{ Multivariate } \\
\hline & & OR & $95 \% \mathrm{CI}$ & OR & $95 \% \mathrm{CI}$ \\
\hline \multicolumn{6}{|c|}{ Has child aged from 12 to 17 years } \\
\hline No & 370 & 1.00 & - & 1.00 & - \\
\hline Yes & 411 & 1.19 & $0.87-1.65$ & 1.30 & $0.78-2.18$ \\
\hline \multicolumn{6}{|l|}{ Gender } \\
\hline Female & 553 & 1.13 & $0.79-1.60$ & 1.44 & $0.79-2.63$ \\
\hline Male & 228 & 1.00 & - & 1.00 & - \\
\hline Age & NA & 0.99 & $0.96-1.02$ & 0.98 & $0.93-1.03$ \\
\hline \multicolumn{6}{|l|}{ Race/ethnicity } \\
\hline Other & 104 & 1.92 & $1.21-3.02$ & 2.08 & $0.92-4.70$ \\
\hline White non-Hispanic & 677 & 1.00 & - & 1.00 & - \\
\hline \multicolumn{6}{|l|}{ Marital status } \\
\hline Married & 504 & 1.12 & $0.80-1.57$ & 1.42 & $0.45-4.53$ \\
\hline Divorced, separated, widow & 177 & 0.99 & $0.68-1.45$ & 0.73 & $0.16-3.38$ \\
\hline Single & 100 & 1.00 & - & 1.00 & - \\
\hline \multicolumn{6}{|l|}{ Education } \\
\hline High school or less & 313 & 1.34 & $0.97-1.85$ & 1.34 & $0.81-2.23$ \\
\hline College degree or higher & 468 & 1.00 & - & 1.00 & - \\
\hline \multicolumn{6}{|c|}{ Confirmed "truth" campaign theme/slogan } \\
\hline No & 626 & 1.00 & - & 1.00 & - \\
\hline Yes & 155 & 1.06 & $0.71-1.57$ & 1.26 & $0.63-2.52$ \\
\hline \multicolumn{6}{|l|}{ Awareness "truth" logo } \\
\hline No & 428 & 1.00 & - & 1.00 & - \\
\hline Yes & 353 & 0.95 & $0.69-1.31$ & 1.02 & $0.57-1.83$ \\
\hline \multicolumn{6}{|l|}{ Confirm "truth" advertising event } \\
\hline No & 253 & 1.00 & - & 1.00 & - \\
\hline Yes & 432 & 0.82 & $0.58-1.17$ & 0.73 & $0.37-1.42$ \\
\hline \multicolumn{6}{|l|}{ Confirm "truth" advertising theme } \\
\hline No & 219 & 1.00 & - & 1.00 & - \\
\hline Yes & 466 & 1.12 & $0.77-1.63$ & 1.26 & $0.63-2.52$ \\
\hline $\begin{array}{l}\text { Awareness of tobacco industry } \\
\text { manipulation theme }\end{array}$ & NA & 1.62 & $1.41-1.86$ & 1.65 & 1.33-2.04 \\
\hline \multicolumn{6}{|l|}{ Doctor's advice to quit } \\
\hline No advice & 420 & 1.00 & - & 1.00 & - \\
\hline Advice to quit & 317 & 1.47 & $1.06-2.04$ & 1.32 & $0.79-2.21$ \\
\hline \multicolumn{6}{|l|}{ Spouse-smoking status } \\
\hline Nonsmoker & 347 & 1.00 & - & 1.00 & - \\
\hline Smoker & 111 & 1.03 & $0.63-1.68$ & 0.81 & $0.44-1.50$ \\
\hline
\end{tabular}

Note. Some cell sizes do not add to 781 due to missing data either because respondents elected not to answer the question or due to a corresponding skip pattern. The term "NA" indicates the variable was continuous and therefore the cell size is not provided.

$\mathrm{OR}=$ Odds Ratio. $95 \% \mathrm{CI}=$ Confidence Intervals. Values in bold are significant based on a 95\% CI. 
according to whether they have children and their own smoking status. We also sought to identify factors from a youth-oriented anti-tobacco media campaign that might have influenced adults to consider quitting smoking within a 30-day time period. We found that about $50 \%$ of adults were aware of each of the various campaign variables, which included an awareness of campaign themes, tobacco truth logo, advertisements, and the tobacco industry manipulation theme.

We also found that a higher percent of adults with children than without children were aware of the campaign theme/slogan; and among those with children, a slightly higher percent were aware of two or more advertisements than adults without children. There were negligible differences in awareness by smoking status. Of all the variables studied, only the variable "awareness of the tobacco industry's manipulation theme" was significantly associated with intentions to quit in the next 30 days in the multivariate model, after controlling for demographic characteristics. This finding is interesting because the Florida "truth" campaign was designed as an intense counteradvertising media campaign purposely portraying the tobacco industry as manipulative, an industry that has lied to youths, and hidden the truth from young people (Sly et al., 2001). Yet, because it was a mass media campaign, unintended audiences were exposed to the campaign message as well. It seems that this particular message (tobacco manipulation) played a role in getting adults who smoke cigarettes to consider quitting in the next 30 days.

The study findings provide evidence that unintended audiences indeed can be reached by the campaign. Although this was a population-based study in Florida, it is important to note that the study sample was predominately white and included only individuals with regular telephone service. Thus, it may have excluded persons of lower socioeconomic status, especially those with unstable housing. It is important to also emphasize that this study does not document the actual behavioral changes of respondents who expressed plans to quit smoking in the next 30 days. Also, despite using data from a population-based study, the sample size was reduced considerably when smokers were selected. Due to this smaller sample size, the racial/ethnic composition of the sample also decreased. To make any meaningful comparisons, we combined black/non-Hispanic, Hispanic, and other into one category with white/non-Hispanic as the reference category. Therefore, we are unable to sufficiently represent adults from these various racial/ethnic groups in this study.

Next, we recognize that the data for most of the campaign, advertising, and smoking variables are self-reports. While this could potentially present a problem, we feel these items captured the respondents' behaviors. Awareness of the campaign and advertisements are measured with self-reports; yet, respondents were asked to confirm their answers by providing specific details about the campaign and the advertisements in order to be counted as confirmed. This was done without providing participants with additional cues. Finally, the adults in this study could be affected by social desirability when asked if they would be interested in quitting smoking in the next 30 days. However, approximately three-quarters of smokers said no, they would not quit in the next 30 days, suggesting that social desirability may not have been a factor in these findings. It should also be noted that the study did not include any additional contextual variables, such as social networks, which may have played a role in influencing intentions to quit.

With these constraints in mind, it may be that the youth-oriented campaigns should also include hard-hitting information on smoking cessation and not just prevention, especially since they are able to reach a broader audience than the one intended. With that said, it appears that to change the behavior of adults who smoke, it may not be appropriate to have a one-size-fits-all program. The audience segment is important and prevention or cessation efforts must be targeted to reach particular population subgroups to be effective 
(Fiore et al., 2007; Institute of Medicine, 2007). What engages youths differs from what engages adults and influences their behavior change and, therefore, it is important to consider a combination and a wide range of techniques. Such efforts are expensive and will be constrained by limited public money. This further underscores the importance of understanding what types of interventions are effective and for whom. In order to ease the burden of morbidity and mortality from tobacco use in the adult population, the study findings suggest that anti-tobacco campaigns must be specifically developed to target this group.

\section{RÉSUMÉ}

\section{Conscience Adulte d'une Campagne d'Antitabac concentrée par le Jeune: l'Affaire d'Enfants Ayant}

Les Données de Resumen d'une enquête d'utilisation de tabac conduite en 2001 ont été utilisées pour examiner si la campagne de média d'antitabac concentrée par le jeune de Floride, qui s'est concentrée sur le tabagisme de cigarette, a atteint des adultes. La majorité de l'échantillon était Blanche (87\%), avec une education scholaire ou universitaire (85 $\%)$ et plus que la moitie avait des enfants avec les enfants (56\%). Les différences dans la conscience et les intentions d'arrêter parmi les fumeurs adultes avec et sans enfants ont été examinées. Environ $50 \%$ d'adultes étaient conscients de la campagne et la conscience du thème de manipulation exercee par d'industrie du tabac a été associée aux intentions d'arrêter indépendant d'avoir des enfants. Ces conclusions fournissent preuve que les campagnes de média d'antitabac visées pour le jeune peuvent atteindre les adultes;cependant, n'est it pas plus approprie d'utiliser un programme qui peut viser tous les groupes.

\section{RESUMEN}

\section{EI Tener Hijos Influencia el Conocimiento que los Adultos Tienen de una Campaña Contra el Tabaco Enfocado en Jóvenes?}

Datos de una encuesta de tabaco hecha en el año 2001 fueron analizados para ver si la campaña contra el tabaco, que se enfoca en jóvenes en el estado de Florida, llegó a los adultos. La mayoría de los participantes fueron no minorías étnicas (87\%), habían completado su educación superior o estudios universitarios (85\%), y más de la mitad tenía hijos (56\%). Se compararon las diferencias del conocimiento e intenciones de dejar de fumar entre adultos que fuman con y sin hijos. Aproximadamente un 50\% de los adultos tenían conocimiento de la campaña, y, el conocimiento del tema de la manipulación de las compañías de tabaco estaba relacionado con intenciones de dejar de fumar, independiente de si los adultos tienen hijos. Los resultados indican que programas enfocados en jóvenes si alcanzan a los adultos; sin embargo, para cambiar el comportamiento de adultos que fuman cigarrillos, es posible que el tener programas generales no sea la mejor estrategia. 


\section{THE AUTHORS}

Jorge Delva, Ph.D., M.S.W., a native of Chile, is Professor in the School of Social Work and Faculty Associate at the Institute for Social Research at the University of Michigan. $\mathrm{He}$ is the codirector of the Vivian A. and James L. Curtis School of Social Work Research and Training Center, a Center that fosters interdisciplinary externally funded research. His work involves studying the effect and trends of individual risk and protective factors on substance use and childhood obesity, while taking into account neighborhood and other contextual level factors, with a particular focus on racial and ethnic differences. He has two wonderful daughters and in his spare time he practices martial arts and enjoys outrigger canoe paddling.

Noella A. Dietz, Ph.D., a sociologist, is a Research Assistant Professor at the University of Miami Miller School of Medicine, in the Department of Epidemiology and Public Health. This appointment is affiliated with the Sylvester Comprehensive Cancer Center. Dr. Dietz began working full-time in the field of tobacco control in 2000, where she worked on all phases of the Florida "truth" campaign evaluation, from sample design and questionnaire construction to data analyses. As a postdoctoral fellow at the University of Miami, Dr. Dietz specialized in tobacco media campaign evaluation, including those done in Florida and Minnesota. In addition, she was involved in examinations of secondhand smoke exposure issues in young adults residing in Florida. Dr. Dietz currently is the Principal Investigator for the James and Esther King Biomedical Research New Investigator grant examining the effects of eliminating anti-tobacco programs for youths. She also is a coinvestigator for a project undertaking a comprehensive study of tobacco-associated cancers in Florida as well as studying secondhand smoke effects in worker groups. Dr. Dietz is also the Principal Investigator for an Institutional American Cancer Society grant investigating how relationship dynamics help or inhibit women's smoking cessation efforts. Finally, Dr. Dietz is the Principal Investigator for the 2008 Tobacco Control Media Evaluation Project currently taking place in Florida. Her work has appeared in prominent peer-reviewed journals, including the Journal of the American Medical Association, Morbidity and Mortality Weekly Report, Preventive Medicine, Drug and Alcohol Dependence, and the Journal of Community Health.

Brian E. Perron, Ph.D., is an Assistant Professor of Social Work at the University of Michigan. He studies services for persons with substance use disorders and psychiatric disorders, with an emphasis on their cooccurrence. The focus of his work involves issues related to treatment process, treatment utilization, and the quality of care. He currently teaches social work courses on the diagnosis and treatment of substance use and psychiatric disorders. Prior to his doctoral training, Dr. Perron worked as a clinical social worker.

Ninive Sanchez, M.S.W., is the project coordinator for the Santiago Longitudinal Study, a NIDA-funded longitudinal study of drug use among adolescents and their families in Santiago, Chile. Her research interests include community-based intervention work, minority populations, and parent-child health, and mental health. 
Michael E. Woolley, D.C.S.W., Ph.D., is an assistant professor in the School of Social Service Administration at the University of Chicago. His research and teaching interests revolve around the risk and protective factors in the social environments of family, neighborhood, and school that impact youth development and school success, and direct social work practice with children and families. Dr. Woolley has extensive direct practice experience working with children, youth, and families in both school and mental health settings. In his time away from work he enjoys kayaking, tennis, and hiking.

\section{Glossary}

CDC Behavioral Risk Factor Surveillance System (BRFSS): The Behavioral Risk Factor Surveillance System (BRFSS) is the world's largest, on-going telephone health survey system, tracking health conditions and risk behaviors in the United States yearly since 1984.

Channeled Rebellion: A focused effort to refuse to accept the perceived authority of the tobacco industry.

Computer Assisted Telephone Interview (CATI) and Random Digit Dialing (RDD): Computer-Assisted Telephone Interviewing Software.

Empowerment Model: A broadly defined health care model focusing on promoting patient involvement in treatment decision-making through increased access to information, knowledge, and self-efficacy.

Florida Pilot Program on Tobacco Control: An anti-tobacco media campaign developed in the late 1990s created as part of the settlement between the state of Florida and the tobacco industry.

Transtheoretical Model: A model that explains or predicts individual processes of behavior change. A key part of the model is that the individual moves through a series of stages. The stages include precontemplation, contemplation, preparation, action stage, and maintenance.

\section{References}

Arheart, K. L., Sly, D. F., Trapido, E., Rodríguez, R., Ellestad, A. (2004). Assessing the reliability and validity of anti-tobacco attitudes/beliefs in the context of a campaign strategy. Journal of Preventive Medicine, 39:909-918.

Centers for Disease Control and Prevention. (2003). Designing and implementing an effective tobacco counter-marketing campaign. Atlanta, GA: US Department of Health and Human Services, National Center for Chronic Disease Prevention and Health Promotion, Office of Smoking and Health.

Fiore, M. C., Croyle, R. T., Curry, S. J., Cutler, C. M., Davis, R. M., Gordon, C., Healton, C., Koh, H. K., Orleans, C. D., Richling, D., Satcher, D., Seffrin, J., Williams, C., Williams, L. N., Keller, P. A., \& Baker, T. B. (2007). Preventing 3 million premature deaths and helping 5 million smokers quit: A national action plan for tobacco cessation. American Journal of Public Health, 94:205-210.

Florida Department of Health Bureau of Epidemiology. (2000). The health and economic impact of tobacco use in Florida. Tallahassee, Fl: Author.

Institute of Medicine. (2007). Ending the tobacco problem: A blueprint for the nation. Washington, DC: The National Academy Press. 
Siegel, M., Biener, L. (2000). The impact of an anti-smoking media campaign on progression to established smoking: Results of a longitudinal youth study. American Journal of Public Health, 90:380-386.

Sly, D. F., Hopkins, R. S., Trapido, E., Ray, S. (2001). Influence of a counter-advertising media campaign on initiation of smoking: The Florida "truth" campaign. American Journal of Public Health, 91:233-238.

Sly, D. F., Heald, G., Ray, S. (2001). The Florida "truth" anti-tobacco media evaluation: Design, first-year results, and implications for planning future state media evaluations. Tobacco Control, 10:9-15.

US Department of Health, Education, and Welfare. (1964). Smoking and health: Report of the advisory committee of the surgeon generalofthe public health service source. Washington, DC: US Printing Office.

US Department of Health and Human Services. (1989). Reducing the health consequences of smoking: Nicotine addiction. Washington, DC: US Printing Office.

US Department of Health and Human Services. (1994). Preventing tobacco use: A report to the surgeon general. Washington, DC: US Printing Office.

US Department of Health and Human Services. (2000). Reducing tobacco use: A report to the surgeon general. Atlanta, GA: DHHS, CDC, National Center for Chronic Disease Prevention and Health Promotion, Office of Smoking and Health.

US Department of Health and Human Services. (2006). Surgeon general's reports on smoking and tobacco use. Atlanta, GA: DHHS, CDC, National Center for Chronic Disease Prevention and Health Promotion, Office of Smoking and Health. 